\author{
Sylwia Skuza \\ Uniwersytet Mikołaja Kopernika \\ sylwia14@umk.pl
}

\title{
CRISTINA AGOSTI-GAROSCI I CLOTILDE GAROSCI - ZAPOMNIANE TŁUMACZKI NAJWIĘKSZYCH DZIEE LITERATURY POLSKIE NA JĘZYK WŁOSKI
}

DOI: http://dx.doi.org/10.12775/RP.2018.012

Zarys treści: Cristina Garosci i jej siostra Clotilde urodziły się w Turynie w drugiej połowie XIX wieku. Obydwie ukończyły filologię romańską, a polskiego nauczyły się same - korzystając z nielicznych książek do nauki tego języka, które w owym czasie dostępne były we Włoszech. Dokonały przekładów największych dzieł polskiej literatury indywidualnie lub (nierzadko) współpracując ze sobą. Przedstawienie sylwetek obydwu tłumaczek jest istotne ze względu na fakt, że są one w Polsce praktycznie nieznane, choć na początku XX wieku to właśnie one przybliżyły włoskiemu odbiorcy utwory między innymi: H. Sienkiewicza, J. Słowackiego, A. Mickiewicza, B. Prusa, S. Żeromskiego, Z. Krasińskiego.

Słowa kluczowe: Garosci, przekład, język włoski, literatura, XIX wiek, XX wiek

Ciostry Clotilde i Cristina Garosci (ta druga po ślubie Agosti-Garosci) weSzły do historii włoskiej polonistyki w głównej mierze dzięki tłumaczeniom największych dzieł polskiej literatury XIX i XX wieku. Przekładały różne gatunki literackie: powieści, poezję, sztuki teatralne, również powieści dla młodzieży, przede wszystkim z epoki romantyzmu i pozytywizmu. Liczba dzieł, które zdołały przełożyć na język włoski, a także kunszt językowy (w czasach im współczesnych prace sióstr Garosci uznawano za stojące na najwyższym poziomie, choć zdarzały się oczywiście także i krytyczne oceny ich przekładów) sprawiły, że powinny one być jednymi z najjaśniejszych postaci w panteonie nie tylko włoskich polonistów, ale i tłumaczy największych 
dzieł literatury polskiej. Tak jednak się nie stało: dopiero od kilku lat widać próby przywracania nazwisk obydwu tłumaczek pamięci dzisiejszych italianistów i polonistów. Warto tu wymienić tytuły dwóch pierwszych artykułów naukowych w języku włoskim, poświęconych Clotilde i Cristinie Garosci: Cristina Agosti Garosci (1881-1966) Mikołaja Sokołowskiego z 2013 roku oraz Le sorelle Garosci traduttrici dal polacco Alessandro Amenty z 2014 roku.

We współczesnych Włoszech literatura polska - zaliczana tu do tzw. literatury mniejszej (letteratura minore) - nie cieszy się popularnością, a wznowienia dzieł jej największych pisarzy (może oprócz Quo vadis Sienkiewicza) z XIX i XX wieku są prawdziwą rzadkością. Jeżeli jednak do takich wznowień dochodzi, to w $50 \%$ przypadków nazwisko tłumaczy jest jedno: Garosci.

Jeszcze 10 lat temu w Polsce nie można było znaleźć zbyt dużo informacji o siostrach Garosci. W pracy Literatura polska: przewodnik encyklopedyczny z 1986 roku znajdziemy pierwsze krótkie hasło biograficzne (Krzyżanowski, Hernas 1986), odnoszące się wyłącznie do Cristiny Agosti-Garosci, a zaledwie od kilku lat w internetowej encyklopedii PWN możemy pod hasłem Agosti-Garosci Cristina przeczytać:

ur. 26 IV 1881, Turyn, zm. 2 V 1966, tamże, wł. tłumaczka i popularyzatorka literatury polskiej; działaczka Inst. Kultury Pol. w Turynie; liczne artykuły o literaturze pol., przekłady i opracowania kryt. dzieł pisarzy pol. (m.in. H. Sienkiewicza, B. Prusa, S. Żeromskiego), często wspólnie z siostrą Clotilde Garosci' ${ }^{1}$.

Także w Wikipedii ${ }^{2}$ od kilku lat jest hasło Cristina Agosti-Garosci, wprawdzie $\mathrm{z}$ obszerniejszymi informacjami, ale i tak niepełnymi, a w wielu miejscach nieprecyzyjnymi.

Z dwóch sióstr Garosci bez wątpienia bardziej znana była Cristina, na co wskazują powyższe przykłady. Clotilde, starsza siostra Cristiny, była wątłego zdrowia, w związku z czym zwykle wykonywała swoją pracę w domu i nie była $\mathrm{w}$ stanie udzielać się na zewnątrz $\mathrm{w}$ rozmaitych przedsięwzięciach i ruchach, co aktywnie czyniła Cristina. Niestety o Clotilde Garosci nie ma żadnych (ani polskich, ani włoskich) biograficznych wzmianek, jej imię pojawia się tylko w kontekście przekładu dzieł literatury polskiej lub obok imienia i nazwiska siostry. W archiwach rzymskiej Biblioteki Narodowej Vittorio

${ }^{1}$ https://encyklopedia.pwn.pl/haslo/Agosti-Garosci-Cristina;3866359.html, (dostęp: 4 kwietnia 2016 r.).

${ }^{2}$ https://pl.wikipedia.org/wiki/Cristina_Agosti-Garosci\#Przek.C5.82ady.5B2.5D, (dostęp: 4 kwietnia 2016 r.). 
Emanuele II znajduje się manuskrypt „Mowy pogrzebowej ku czci Clotilde Garosci, tłumaczki polskiej"3, której autorem był pisarz Leonardo Lattarulo. Nieznana jest dokładna data śmierci Clotilde, ale A. Amenta (2014) wspomina, że zmarła ona podczas II wojny światowej. O śmierci Cristiny wspomina z kolei prof. Roman Pollak (1966a).

Cristina Garosci (a właściwie Paola Maria Cristina Garosci) i jej siostra Clotilde były córkami Giovanniego i Celestiny (z domu Armissoglio). Rodzina Garosci, pochodzenia liguryjsko-piemonckiego, utrzymywała się z handlu olejem i z działalności rodzinnej fabryki konserw. Obydwie siostry były absolwentkami romanistyki na uniwersytecie w Turynie (jednymi z pierwszych kobiet studiujących na tej uczelni). Wiadomo, że Cristina na tym samym uniwersytecie, w 1905 roku uzyskała stopień doktora na podstawie dyserta$\mathrm{cji}^{4}$ o Małgorzacie z Nawarry (Margherita di Navarra, 1492-1594), opublikowanej w 1908 roku. W 1905 roku poślubiła lekarza Mario Agosti i od tego czasu używała podwójnego nazwiska: Agosti-Garosci. Ze związku narodziło się jedyne dziecko pary - syn Giorgio ${ }^{5}$ (1910-1992), który był historykiem prawa, polonofilem, a także członkiem zarządu Instytutu Kultury Polskiej im. A. Begeya w Turynie (Borgna 2015).

Polskiego Clotilde i Cristina nauczyły się same, korzystając z nielicznych książek do nauki tego języka, które w owym czasie dostępne były we Włoszech. Fakt ten świadczy o ich niezwykłych zdolnościach językowych - pamiętajmy, że ponad 100 lat temu nikt nie marzył o nagraniach audio do nauki obcego języka. Powody, dla których siostry Garosci nauczyły się polskiego, a następnie gorąco popularyzowały literaturę polską nie tylko jej przekładami, ale także wprowadzeniami oraz artykułami naukowymi i prasowymi, które przedstawiały tę literaturę włoskiemu odbiorcy, związane były ściśle z panującą ówcześnie sytuacją polityczną Europy. Bez wątpienia jednym z istotnych czynników, który sprawil, że Cristina, mimo romanistycznego wykształce-

${ }^{3}$ Elogio funebre in favore di Clotilde Garosci, tradutrice polacca. http://manus.iccu.sbn.it// opac_SchedaScheda.php?ID=0000148481 (dostęp: 2 kwietnia 2016 r.).

${ }^{4}$ Książka Margherita di Navarra (1492-1594), powstała na podstawie dysertacji, została opublikowana w 1908 roku w Turynie.

${ }^{5}$ Ze względu na lewicujące i antyfaszystowskie poglądy Giorgio był zmuszony do ucieczki z Włoch do Francji za czasów dyktatury Mussoliniego. Do 1942 roku przebywał za granicą, gdzie aktywnie działał we włoskim antyfaszystowskim ruchu oporu Giustizia e Libertà (Sprawiedliwość i Wolność) (Borgna 2015). Po powrocie do kraju był współzałożycielem partii Partito d’Azione, która funkcjonowała również po wojnie w opozycji do chrześcijańskiej demokracji (Democrazia Cristiana). Wydaje się, że matka Giorgia, Cristina, po części sympatyzowała z lewicującymi poglądami syna, o czym może świadczyć powojenny dobór niektórych nazwisk polskich pisarzy do tłumaczenia, np. Gustaw Morcinek. 


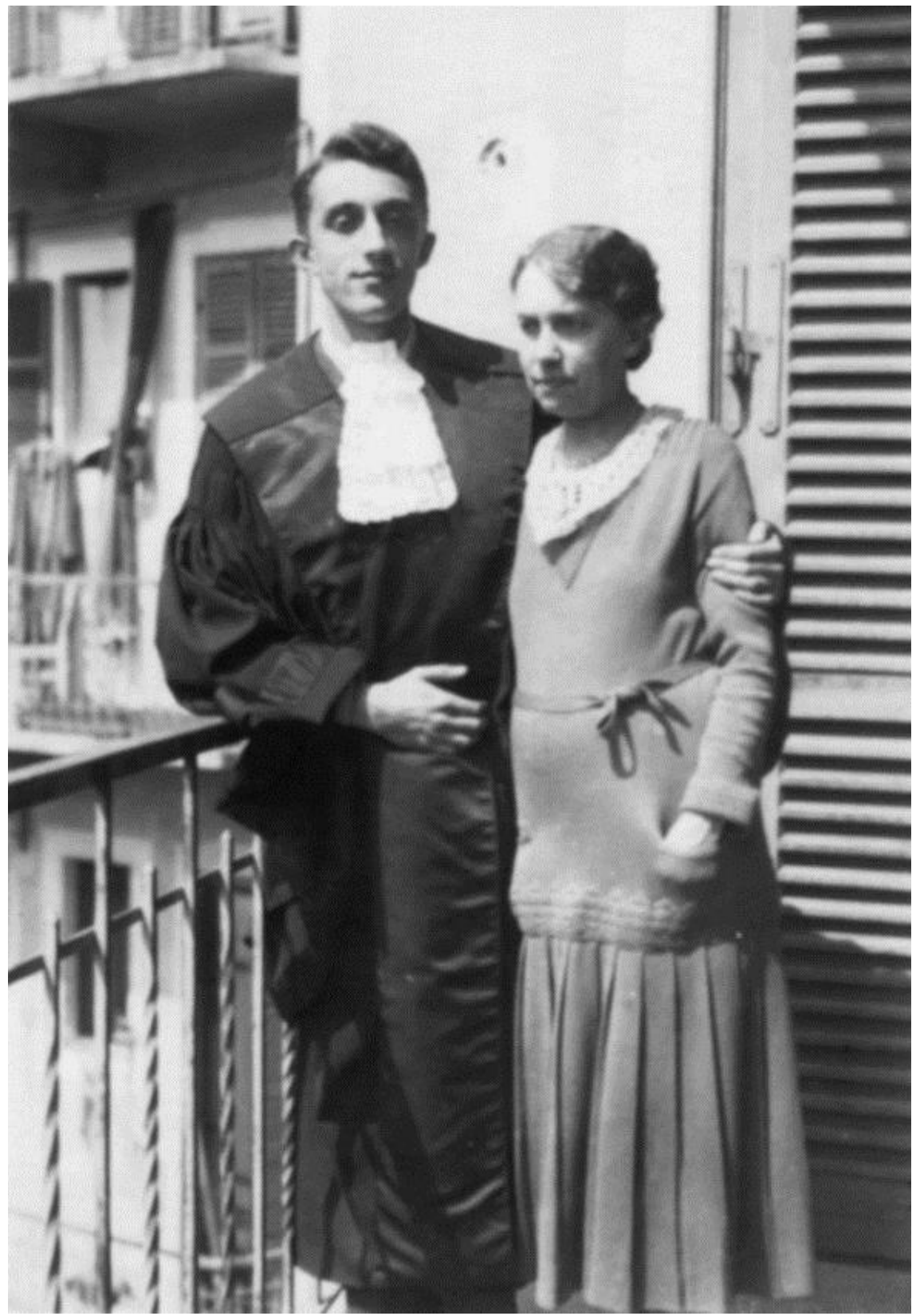

Cristina Agosti-Garosci z synem Giorgio Agosti, Turyn 1935 rok 
nia, zainteresowała się literaturą i kulturą polską, była znajomość z włoskim polonofilem Atillo Begeyem (1843-1928). Włączyła się ona nawet w prace działającego w Turynie w czasach I wojny światowej Komitetu „Pro Polonia”6 i w pomoc jeńcom wojennym armii austriackiej, wśród których były osoby narodowości polskiej ${ }^{7}$. Poznanie historii narodu bez państwa, zmuszanego do walki w armiach zaborców spowodowało, że Cristina i Clotilde postanowiły nauczyć się języka i przetłumaczyć polskie dzieła literackie, aby stały się one Włochom nie tylko znane, ale ze względu na podobną historię niepodległościową (Włochy są jednym państwem zaledwie od 1861 roku) także bliskie.

W kolejnych latach Cristina Agosti-Garosci była działaczką Koła Przyjaciół Polski, działała także w zarządzie założonego w 1930 roku Instytutu Kultury Polskiej w Turynie. W sierpniu 1928 roku przyjechała jedyny raz do Polski, gdzie w Zakopanem profesor Roman Pollak (1886-1972) zorganizował kurs dla włoskich polonistów. Na zebraniach o charakterze seminaryjnym wygłosiła odczyt o religijności Adama Mickiewicza. Podczas tego pobytu zgromadziła materiały do tych tłumaczeń literatury polskiej, które miała w najbliższych planach. W czasie II wojny światowej Cristina działała w antyfaszystowskim ruchu oporu. Po wojnie państwo polskie odznaczyło ją Krzyżem Oficerskim Orderu Odrodzenia Polski ${ }^{8}$.

Należy wspomnieć, że Cristina Agosti-Garosci zajmowała się nie tylko przekładem dzieł polskiej literatury ${ }^{9}$, wśród jej zainteresowania znajdowały się także literackie studia komparatystyczne, zawsze jednak dotyczące sytuacji Polski wpisanej w konteksty międzynarodowe. Publikowała liczne artykuły dotyczące historii polskiej literatury w pismach takich jak „Rivista di Letterature Slave”, „Europa Orientale”, „La Vita italiana”, „Nuova Antologia”, "Giornale Storico della letteratura Italiana”. Była również współautorką Di-

${ }^{6}$ Komitet „Pro Polonia”, założony w 1915 roku przez A. Begeya, powstał w celu poruszenia włoskiej opinii publicznej sprawami polskimi. Należała do niego elita Turynu: rektor uniwersytetu, arystokraci, posłowie, wojskowi. Komitet był aktywny na wielu płaszczyznach począwszy od pisania petycji do parlamentu, przez organizowanie konferencji i koncertów, a skończywszy na pomocy Polakom przebywającym na terenie Piemontu (Jaworska 2007: 162-164).

${ }^{7}$ Na przełomie 1918 i 1919 roku w obozie La Mandria di Chivasso (region piemoncki) były formowane polskie oddziały wojskowe złożone z jeńców armii austro-węgierskiej i niemieckiej. Oddziały te zostały wiosną 1919 roku przetransportowane do Francji i wcielone do Armii gen. Józefa Hallera. Większość z nich, już w wolnej Polsce, będzie uczestniczyła w wojnie obronnej przeciwko Rosjanom w 1919 i 1920 roku. W obozie przeszkolono około 20000 przyszłych żołnierzy gen. Hallera, jednak warunki tam panujące były skrajnie trudne (Jaworska 1999).

${ }^{8} \mathrm{http}: / /$ www.wiadomosci24.katowice.pl/d/Cristina_Agosti-Garosci (dostęp: 4 kwietnia 2016 r.).

9 Warto zauważyć, że Agosti-Garosci tłumaczyła także z języka czeskiego na język włoski. 
zionario di centouno capolavori delle letterature slave (Słownik stu jeden dziet literatur słowiańskich), pracy wydanej pod redakcją Eridano Bazzarellego.

Dokonywany przez obie siostry wybór literatury do przekładu nigdy nie był przypadkowy. Motywacją była dla nich idea romantycznej tradycji, współpracy włosko-polskiej wspierającej aspiracje wolnościowe Polaków pod zaborami. Siostry Garosci były pod wrażeniem towianizmu, filozofii stworzonej przez Andrzeja Towiańskiego (1799-1878), mistyka i reformatora religijnego, którego myśl wywarła ogromny wpływ na polski romantyzm, w tym na dzieła Adama Mickiewicza i Juliusza Słowackiego. Towiański, będąc już na emigracji w Paryżu, propagował koncepcję roli Polski jako państwa wyrzekającego się nienawiści do Rosji, porzucającego walkę o wyzwolenie, wprowadzającego Europę w doskonalszą epokę chrześcijaństwa. Siostry Garosci wierzyły, że literatura polska znajduje swoją najdoskonalszą formę w dziełach romantyków i że w nich właśnie odnajduje swoją duchową odnowę przezwyciężając tradycyjny polski pesymizm.

Jak już wspomniano, prócz wstępów do polskich dzieł literackich Cristina była autorką licznych publikacji naukowych przybliżających polską i nie tylko polską literaturę: między innymi La genesi di un grande poema: il signor Taddeo (Geneza wielkiego poematu: Pan Tadeusz; 1917), Il fascino poetico dell'Italia e Maria Konopnicka (Maria Konopnicka i poetycka fascynacja Italia; 1926), Edizioni Kochanowskiane nella Biblioteka Narodowa (Wydania dziet Kochanowskiego w Bibliotece Narodowej ${ }^{10}$; 1930), Mickiewicz e la Russia (Mickiewicz i Rosja; 1940), Enrico Sienkiewicz scrittore per fanciulli (Henryk Sienkiewicz pisarz dla młodzieży; $\left.1946^{11}\right)$.

Cristina pisała wstępy zarówno do książek opublikowanych za życia Clotilde, jak i do wznowień ukazujących się już po śmierci starszej z sióstr, dlatego bardzo często to właśnie Cristinie przypisuje się również te przekłady, których dokonała wyłącznie Clotilde. Wstępy do przełożonych powieści polskich były niezwykle istotne, a Cristina - literaturoznawczyni i polonofilka - miała niezwykłą umiejętność przybliżenia zwykłemu włoskiemu odbiorcy nie zawsze łatwej literatury innego narodu. Choćby na przykładzie wstępu do Pana Tadeusza można zobaczyć, że potrafiła wprowadzić przyszłego odbiorcę w klimat polskiej epopei narodowej, nie tylko odnosząc się do sytuacji społeczno-politycznej, ogromnie istotnej dla akcji Pana Tadeusza, ale także zwracając uwagę przyszłego czytelnika na inne aspekty dzieła. Pisała tam:

${ }^{10}$ Był to specjalny numer poświęcony stuleciu urodzin Jana Kochanowskiego.

${ }^{11}$ Szczegółowe podsumowanie publikacji naukowych oraz recenzje twórczości Cristiny Agosti-Garosci zob. Amenta 2014: 6-9. 
poeta wspomina swoją Litwę, kraj o walorach przyrodniczych wyjątkowych na całą Europę, o bezkresnych puszczach, o bogactwie i intensywności zieleni, której ludzkie oko nie jest w stanie przeniknąć, a ludzka stopa nigdy jeszcze nie przebyła, z czeluści której wydobywa się pomruk niedźwiedzia i dzikiego żubra, a ludzka wyobraźnia ubiera te lasy w tysiące legend. (Mickiewicz 1955: XXI)

Dorobek przekładowy obydwu sióstr Garosci jest ogromny. Przetłumaczona przez Clotilde Garosci literatura polska, ze wstępami siostry, to:

Pan Tadeusz (1834) Adama Mickiewicza (Pan Taddeo Soplitza, Carabba Editore, Lanciano 1924); w 1955 roku, już po śmierci siostry, Cristina ponownie wydaje książkę (Einaudi, Turyn), tym razem pod tytułem Pan Tadeusz, wraz ze wstępem, poprawkami oryginalnego tłumaczenia oraz dodanym Epilogiem, którego Clotilde nie znała. Wyjątkowość przekładu Pana Tadeusza na język włoski wynika przede wszystkim z faktu, że był on pierwszym dokonanym bezpośrednio z języka polskiego. Wcześniejsze tłumaczenie Pana Tadeusza, z 1871 roku, którego autorstwo przypisuje się włoskiemu poecie Arrigo Boito (1842-1918), zostało dokonane z języka francuskiego i powieliło, a raczej pomnożyło błędy, które znajdowały się w wersji francuskiej. I tak $\mathrm{np}$. ciche grusze $\mathrm{z}$ Prologu to $\mathrm{w}$ wersji Boito pometi dalle foglie cenerognole, czyli „jabłonie o poszarzałych liściach”, a niezapomniane gryka jak śnieg biała oraz dzięcielina pałająca rumieńcem w ogóle zniknęły (Skuza 2010: 18-19). Obydwa tłumaczenia Pana Tadeusza zostały napisane prozą, jednak uważa się, że przekład Clotilde Garosci do dziś jest najlepszym i najwierniejszym tłumaczeniem epopei Mickiewicza na język włoski. W tym miejscu warto także wspomnieć, że powstał przekład Pana Tadeusza pisany wierszem, autorstwa Oskara Skarbka-Tłuchowskiego (1893-1976), jest to jednak tłumaczenie zaledwie kilku pierwszych ksiąg.

- Irydion (1835) Zygmunta Krasińskiego (Iridione, Associazione „Adamo Mickiewicz”, Rzym 1926), z przedmową Cristiny Agosti-Garosci. Jako ciekawostkę warto podać, że ten pierwszy przekład Irydiona na język włoski siostry zadedykowały Benito Mussoliniemu ${ }^{12}$.

- Wszystko i nic. Wybór nowel (1914) Stefana Żeromskiego (Tutto e Nulla e altre novelle, Slavia, Turyn 1928). Przekładu dokonały wspólnie Clotilde i Cristina. Giovanni Maver (1891-1970), włoski slawista, admirator tłumaczeń sióstr Garosci, w odniesieniu do tego przekładu

${ }^{12}$ Krytycy literatury interpretują owe dedykacje dla Mussoliniego jako początkowy wyraz sympatii dla zewnętrznej i wewnętrznej polityki Duce, szczególnie w stosunku do Kościoła katolickiego i próby uczynienia katolicyzmu religią państwową. Przypomnijmy jednak, że podczas II wojny światowej obydwie siostry Garosci działały w antyfaszystowskim ruchu oporu. 
pisał: „Tłumaczenie jest świetne pod każdym względem. Porównując je z niektórymi fragmentami oryginału nie możemy nie podziwiać doskonałej jakości przekładu obydwu tłumaczek, które potrafiły oddać w szlachetnej i precyzyjnej formie cały kunszt i bogactwo sztuki Żeromskiego" (Maver 1929: 281).

- Italia (1901) Marii Konopnickiej (Italia: liriche, Istituto per l'Europa Orientale, Rzym 1929). Wersja prozą i wstęp Cristiny Agosti-Garosci.

- Popioły (1903) Stefana Żeromskiego (Ceneri, Slavia, Turyn 1930). Wstęp i przypisy Cristina Agosti-Garosci; wznowienie powieści przez turyńskie Einaudi w 1946 roku - tu (po dokonaniu korekty językowej oryginalnego tłumaczenia) Cristina widnieje już obok Clotilde jako współtłumaczka ${ }^{13}$. Przekład dwóch tomów Popiołów został doceniony przez polskich krytyków ze względu na wierność ${ }^{14}$, jednak można także znaleźć głosy krytyczne dotyczące jakości tłumaczenia.

- Kordian oraz Mazepa (1833) Juliusza Słowackiego (Kordjan. Mazep$p a$, Unione tipografico-editrice torinese, Turyn 1932). Dzieła te wznawiano później w 1942, 1946, 1947, 1956 i 1967 (Kordian. Mazeppa) roku i zawsze wydawane były przez turyńskie wydawnictwo U.T.E.T. (Unione tipografico-editrice torinese).

- Clotilde tłumaczyła także wiersze Kazimierza Przerwy Tetmajera, Leopolda Staffa i Jana Kasprowicza ${ }^{15}$, których włoskie przekłady, określane jako liriche varie (zbiór wierszy), pojawiały się w czasopiśmie „Rivista di Letterature Slave” („Czasopismo Literatur Słowiańskich”) w 1926 roku (poezje Kasprowicza), a także w „I nostri Quaderni” („Nasze Zeszyty”) z 1927 roku (przekład utworów Przerwy Tetmajera, Wyspiańskiego i Staffa).

${ }^{13}$ Prof. Pollak wspominał: „Parafraza angielska Popiołów obcinała całość oryginału o jedną czwartą tekstu, jeszcze gorzej było z przekładem francuskim. Włoski zaś przekład był całkowity. Praca nad nim ciągnęła się przez dwa lata z górą. Na kurs dla włoskich polonistów w Zakopanem w r. 1928 przywiozła pani Agosti całą litanię przytrudniejszych zwrotów i zasięgała rady prof. Nitscha. Przyszło nawet docierać do włoskich regulaminów wojskowych z doby napoleońskiej, aby wiarogodnie odtworzyć rozkazy piechotne i artyleryjskie w opisie bitwy pod Falentami. Wstęp 18-stronicowy zawiera pogląd na rozwój powieści historycznej w Polsce, uwagi o stosunku Popiołów do Wojny i pokoju Tołstoja oraz szereg spostrzeżeń syntetycznych. Zanotowano w prasie włoskiej około 20 dłuższych i krótszych recenzji tego przekładu” (Pollak 1966a: 701).

${ }^{14}$ Warto wspomnieć w tym miejscu artykuł Romana Pollaka poświęcony tłumaczeniom Cristiny Agosti-Garosci ze szczególnym uwzględnieniem przekładu Popiołów Żeromskiego. Zob. Pollak 1966b.

${ }^{15} \mathrm{~W}$ tym przypadku Clotilde nie tylko tłumaczyła polską poezję, ale także pisała do niej wstępy. Zob. Garosci 1926. 
Dokonane przez Cristinę Agosti-Garosci przekłady literatury polskiej to w kolejności:

- Straszny dziadunio (1887) Marii Rodziewiczówny (Un nonno terribile, Istituto Missionario Pia Società S. Paolo, Rzym 1942). Była to pierwsza wersja powieści przetłumaczona na włoski bezpośrednio z języka polskiego.

- Dary wiatru pótnocnego (1938) Wacława Sieroszewskiego (I doni del vento di mezzanotte, Società Apostolato Stampa, Rzym 1946).

- W pustyni i w puszczy (1912) Henryka Sienkiewicza (Per deserti e per foreste, Società Apostolato Stampa, Rzym 1946). W roku 1962 powieść wznowiła Società Azionaria Internazionale Editrice z Turynu, a w latach 1967, 1975 i 1985 mediolańskie wydawnictwo Edizioni Paoline.

- Quo vadis? (1896) Henryka Sienkiewicza (Quo vadis? Romanzo dei tempi di Nerone. Rizzoli, Mediolan 1950, 2v.). W związku z tym, że nie tylko było to najgłośniejsze dzieło Polaka, ale zostało także wyróżnione Nagrodą Nobla, tłumaczono je we Włoszech kilkanaście razy. Wyjątkowość przekładu Cristiny Garosci po raz kolejny wynika $\mathrm{z}$ tego, że był to pierwszy włoski przekład z oryginału. W ogóle pierwszego przekładu Quo vadis na język włoski dokonał, już w 1899 roku, Federico Verdinois (Marinelli 2004: 143), który jednak przetłumaczył tekst z języka rosyjskiego. Kolejne nakłady Quo vadis? w tłumaczeniu Cristiny Agosti-Garosci drukowały wydawnictwa: Rizzoli (Mediolan 1984), Fabbri (Mediolan 1994 i 2001) i BUR (Mediolan 2003).

- Ludzie sa dobrzy (1935) Gustawa Morcinka (Gli uomini sono buoni: racconto per la gioventù, Società Apostolato Stampa, Rzym 1950). To samo wydawnictwo wznowiło tłumaczenie w roku 1953.

- Latarnik i inne nowele (wybór nowel) (1881) Henryka Sienkiewicza (Il guardiano del faro e altre novelle, Rizzoli, Mediolan 1953). W 1970 roku utwór wznowiło wydawnictwo I Nobel letterari z Rzymu.

- Bartek zwycięzca (1882) Henryka Sienkiewicza (Bartek il vincitore e altre novelle, Rizzoli, Mediolan 1955).

- Życie Chopina (1953) Kazimierza Wierzyńskiego (Chopin, Rizzoli, Mediolan 1955), ze wstępem Artura Rubinsteina.

- Krzywe Koło (1946) Kazimierza Konarskiego (Ragazzi nella tormenta: racconto sullo sfondo della vita di Varsavia dal 1939 al 1944, Società Apostolato Stampa, Rzym 1950 i 1957).

- Placówka (1886) Bolesława Prusa (L’avamposto, Rizzoli, Mediolan 1961).

Podsumujmy. Spośród wszystkich tłumaczy dzieł literatury polskiej na język włoski siostry Clotilde Garosci i Cristina Agosti-Garosci dokonały naj- 
większej liczby przekładów. Dorobek ten jest imponujący. W ich przypadku należałoby jednak mówić nie o liczbach, a o jakości, która mimo krytyki (Maver 1929: 306, Sokołowski 2013: 16) nie budzi wątpliwości. Obydwie tłumaczki bardzo dobrze poznały język polski, przekładały wyłącznie z oryginału, a nie, jak zdarzało się to im współczesnym, z wersji w innym języku. Niezwykle cenne (i na bardzo wysokim poziomie) pozostają do dziś napisane przez Cristinę Agosti-Garosci przedmowy do polskich dzieł literackich. Trudno jest jednoznacznie odpowiedzieć na pytanie, dlaczego tłumaczki zostały zapomniane zarówno we Włoszech, jak i w Polsce - Polska ma im przecież bardzo wiele do zawdzięczenia. Jeżeli chodzi o stronę włoską, zapewne fakt ten po części wynika $\mathrm{z}$ ogólnie małego zainteresowania wielkimi dziełami literatury polskiej - Włosi znają zazwyczaj dwa nazwiska: Wisława Szymborska i Gustaw Herling-Grudziński. Do nas należy przywrócenie pamięci o Clotilde Garosci i Cristinie Agosti-Garosci.

\section{Literatura}

Agosti-Garosci, C., 1908, Margherita di Navarra (1492-1594), Torino.

Agosti-Garosci, C., 1917, „La genesi di un grande poema: il signor Taddeo”, [w:] Nuova Antologia.

Agosti-Garosci, C., 1926, „Il fascino politico dell'Italia e Maria Konopnicka”, [w:] La Vita italiana.

Agosti-Garosci, C., 1930, „Edizioni Kochanowskiane nella Biblioteka Narodowa", [w:] Rivista di Letterature Slave, nr 5.

Agosti-Garosci, C., 1931, „Motivi e riflessi mickiewiczani in «Ceneri» di St. Żeromski", [w:] Rivista di Letterature Slave, nr 6, s. 5-16.

Agosti-Garosci, C., 1940, „Mickiewicz e la Russia”, [w:] L'Europa Orientale, nr 20, s. 140-145.

Agosti-Garosci, C., 1946, „Enrico Sienkiewicz scrittore per fanciulli”, [w:] Nel centenario di Enrico Sienkiewicz (1846-1946), Roma, s. 173-177.

Amenta, A., 2014, „Le sorelle Garosci traduttrici dal polacco”, [w:] Maestri della polonistica italiana. Atti del convegno dei polonisti italiani, nr 5, s. 27-35.

Bazzarelli, E. (red.), 1967, Dizionario di centouno capolavori delle letterature slave, Milano.

Bersano Begey, M., 1966, „Cristina Garosci (1881-1966)”, [w:] Ricerche slavistiche, $\mathrm{nr}$ 14, s. 308-310.

Borgna, P., 2015, Il coraggio dei giorni grigi: Vita di Giorgio Agosti, Roma-Bari. 
Garosci, C., 1926, „Liriche varie di Jan Kasprowicz”, [w:] Rivista di Letterature Slave, nr 44, s. 206-208.

Jaworska, K., 1999, „La Mandria di Chivasso. Da prigionieri a uomini liberi: la formazione dell'Armata Polacca in Italia", [w:] La Mandria di Chivasso. Storia di un tenimento Sabaudo, a cura dell'Associazione La Mandria Monumentale, G. Mazzitelli (red.), Chivasso, s.77-105.

Jaworska, K., 2007, „Żołnierz polski we Włoszech - polskie czasopismo w Piemoncie w 1919 roku", [w:] Postscriptum, nr 1 (53), s. 161-171.

Krzyżanowski, J., Hernas, Cz., 1986, Literatura polska: przewodnik encyklopedyczny, t. 1: A-M, Warszawa.

Marinelli, M., 2004, „Quo vadis? Traducibilità e tradimento”, [w:] Semizdat, nr 3, s. 133-134.

Maver, G., 1929, „Narratori polacchi”, [w:] I libri del giorno (1924-1929), nr 5 (XII), s. 305-307.

Mickiewicz, A., 1955, tłum. C. Garosci, Pan Tadeusz, Torino.

Pollak, R., 1966a, „Cristina Agosti (26 kwietnia 1881 - 2 maja 1966) [nekrologi], [w:] Pamiętnik Literacki, nr 4, s. 669-702.

Pollak, R., 1966b, „Na marginesie włoskiego przekładu Popiołów”, [w:] Prace o literaturze i teatrze ofiarowane Zygmuntowi Szweykowskiemu, J. Maciejewski (red.), Wrocław, s. 278-292.

Skuza, S., 2010, „Taddeo Soplitza o L'ultimo processo in Lituania i Pan Taddeo Sopliza di Adamo Mickiewicz - kultura szlachecka we włoskich przekładach dzieła Adama Mickiewicza Pan Tadeusz", [w:] Tłumacz wobec problemów kulturowych, M. Piotrowska (red.), Kraków, s. 17-28,

Sokołowski, M., 2013, „Cristina Agosti Garosci (1881-1996)”, [w:] Rassegna Italiana di Argomenti Polacchi, nr 4, s. 14-17.

\section{Cristina Agosti-Garosci and Clotilde Garosci - the forgotten translators of the greatest works of Polish literature into Italian}

Summary

Cristina Garosci and her sister Clotilde were born in Turin (Italy) in the second half of the $19^{\text {th }}$ century. Both sisters graduated from Romance studies at the University of Turin but what is worth stressing is the fact that they learnt the Polish language by themselves by using not that many textbooks of this language that were available at that time in Italy. The Garosci sisters made individual translations of the greatest works of the Polish literature, but also often worked on their translations together. The presentation of these two translators is essential due to the fact that they are virtually unknown in Poland, although at the beginning of the $20^{\text {th }}$ century they were 
the ones who brought forward the most important works of the Polish fiction e.g. the works of H. Sienkiewicz, J. Słowacki, A. Mickiewicz, B. Prus, S. Żeromski, and Z. Krasiński to the Italian audience. The paper lists all the works of the Polish literature translated by the Garosci sisters. Publishing houses and years of issues of re-edited translations are specified in the article as well.

Keywords: Garosci, translation, Italian language, literature, $19^{\text {th }}$ century, $20^{\text {th }}$ century (c) $\underset{\mathrm{BY}}{\ominus}$ 